\title{
Research on Industrial Waste Heat Utilization Technology
}

\author{
Huazhen LIU \\ North China Electric Power University,Energy and Power \\ Engineering(Practice),Beijing102206,China \\ 1305992161@qq.com
}

\begin{abstract}
Key words: Waste heat utilization, Energy saving and emission reduction, Pure low temperature waste heat power generation, Organic Rankine cycle power generation
\end{abstract}

\begin{abstract}
With the increasingly tense energy situation, energy saving and emission reduction has become an important issue in the current industrial sector. China's industrial waste heat resources are abundant, but the utilization rate of waste heat is low. This paper summarizes the present situation of industrial waste heat utilization resources, and discusses the development of industrial waste heat utilization technology. Corresponding to different industries, this paper focuses on the analysis of several waste heat utilization.
\end{abstract}

\section{Introduction}

Energy is an important material for the survival and development of human society. Energy issue is always the core issue of the people's livelihood, and is also a difficult problem restricting economic development and social progress. At present, there are still many problems in China's energy utilization, such as low efficiency, poor economic returns, and environmental impact. Therefore, energy saving and emission reduction, which improves energy efficiency, is an important way to solve energy use and environmental protection.

"Energy saving and emission reduction work program" is formulated by the National development and Reform Commission and the relevant departments. It further clarified the objectives and the overall requirements of energy saving and emission reduction. Main objectives: as of 2010, the GDP energy consumption from 1.22 tons of standard coal in 2005 dropped to below the standard coal of 1 tons, which means to reduce the amount of about $20 \%$;per unit of industrial added value of water consumption decreased by 30\%[1]. At present, China's energy utilization rate is only about 33\%, lower than the developed countries about $10 \%$, At least $50 \%$ of the industrial energy consumption in various forms of waste heat is directly abandoned[2]. Therefore, the utilization rate of waste heat in China has a lot of room for improvement, and the utilization of industrial waste heat is also very important to the progress of energy saving and emission reduction.

\section{Overview}

Waste heat belongs to the two energy. It is a product of primary energy or combustible material conversion. It may also be the amount of heat that is produced during the combustion of a fuel after the completion of a process. Industrial waste heat is a kind of energy which is not utilized in energy utilization equipment under certain economic conditions. Industrial waste heat includes: waste heat of high temperature waste gas, waste heat of cooling medium, waste heat of waste water, high temperature product and waste heat of slag, chemical reaction waste heat, waste gas of combustible waste gas and waste heat and high pressure fluid residual pressure. 
China has the largest coal coking industry. Metallurgy, steel and cement industries are among the world's leading producers in terms of quantity and output,. These industries produce a large number of flue gas in the production process, which discharged into the air. It not only wastes energy, but also pollutes the environment. According to statistics, the average number of waste heat is up to about 40000000 tons of standard coal[3].

Table 1 Utilization of waste heat of main industries in China[4]:

\begin{tabular}{|c|c|c|c|c|c|}
\hline Industry & $\begin{array}{l}\text { Quantity of } \\
\text { waste heat } \\
\text { resources }\end{array}$ & $\begin{array}{l}\text { Waste heat } \\
\text { rate\% }\end{array}$ & $\begin{array}{l}\text { Recovered } \\
\text { surplus }\end{array}$ & $\begin{array}{c}\text { Residual heat } \\
\text { recovery } \\
\text { rate\% }\end{array}$ & $\begin{array}{c}\text { Residual heat } \\
\text { utilization } \\
\text { potential }\end{array}$ \\
\hline Iron and Steel & 830 & 10.4 & 180 & 21.7 & 650 \\
\hline Coloured & 62 & 4.9 & 20 & 30.8 & 45 \\
\hline Chemical Industry & 620 & 8.8 & 260 & 41.9 & 360 \\
\hline Petrifaction & 680 & 24.5 & 380 & 55.9 & 300 \\
\hline $\begin{array}{l}\text { CHEN Buliding } \\
\text { materials }\end{array}$ & 305 & 3.2 & 85 & 27.9 & 220 \\
\hline Light Industry & 280 & 6.1 & 70 & 21.9 & 210 \\
\hline Spin & 70 & 6.1 & 30 & 42.9 & 40 \\
\hline Coal & 70 & 2.2 & 30 & 42.9 & 40 \\
\hline Mechanics & 120 & 3.1 & 20 & 16.7 & 100 \\
\hline Total/Average & 3040 & 7.3 & 1075 & 34.9 & 1965 \\
\hline
\end{tabular}

From table 1: the major industrial sectors of China's quantity of waste heat resources is 30 million 400 thousand tons of standard coal. Waste heat resources average rate is $7.3 \%$. The heat quantity is huge, but the recovery rate is only $34.9 \%$. Thus, improving the heat recovery rate is an important issue to improve energy utilization and energy saving and emission reduction.

\section{Status of industrial waste heat utilization}

Iron and steel industry. In our country, the iron and steel industry belongs to the field of energy consumption. In the total energy consumption of the major industrial sectors in China, the energy consumption of the iron and steel industry accounts for about $20 \%$ of the total, but the recovery rate is only about $21.7 \%$. Iron and steel industry waste heat resources are very rich. So it is necessary to carry out recycling of waste heat in steel production.

The main sources of waste heat are coke and the flue gas of sintering, converter and heating furnace in iron and steel enterprises. Statistics show that a large number of tons per year, large and medium-sized enterprises in China will produce 8.44 of the total energy consumption per ton steel in about $37 \%$ of the proportion. In the total amount of waste heat: Intermediate or final products carried by the sensible heat accounted for about 39\% of the proportion; the sensible heat of all kinds of slag is about $9 \%$; the sensible heat of waste gas is about $37 \%$; the sensible heat of cooling water accounts for about $15 \%$. From the above analysis, we can find that there are a lot of waste heat resources in the iron and steel industry [5].

At present, the waste heat recovery technology used in the iron and steel enterprises in China mainly includes: converter gas recovery and utilization technology, blast furnace top waste heat 
power generation technology, sintering waste heat power generation technology, heat pipe waste heat recovery technology and so on.

Cement industry. Cement industry is a traditional industry in China ,and it is also one of the important pillars of the national economy.

There is a large amount of waste heat in the cement kiln, the heat loss from the exhaust gas from the first stage preheater of the kiln and the heat loss from the exhaust gas from the kiln head cooling machine account for nearly $50 \%$ of the total heat. Cement kiln waste heat utilization has two main aspects, one is the process of their own use, and the other is a large part of the remaining heat used for waste heat power generation. At present, our country often use pure low temperature waste heat power generation technology.

There are many cement enterprises in our country, but the technology is different. Among them: there are a number of technology is relatively backward and high energy consumption in shaft kiln production line (the proportion of the production capacity by 2003 has been reduced by $72 \%$ to 55\% in 2005); and the advanced technology of new dry cement technology in production. It has the advantages of high quality, high efficiency, low consumption and environmental protection. At the same time, it can also greatly improve the thermal efficiency[6].

Petrochemical industry. The energy consumption of petrochemical industry accounts for about $16 \%$ of total industrial energy consumption. Sinopec only consumes about 40 million tons of fuel per year, a large part of which is lost in the form of waste heat. During the production process of petrochemical enterprises, the residual heat of low-temperature is huge, which is mainly distributed in the atmospheric and vacuum distillation, catalytic cracking, hydrogenation of diesel oil and gasoline hydrogenation and other devices. Survey shows that this part of the low temperature waste heat accounts for about $60 \%-80 \%$ of the total low-temperature waste heat. It is of great strategic significance to achieve the goal of energy saving and emission reduction, reduce the efficiency and enhance the competitiveness of enterprises. How to make use of these low temperature waste heat is also a problem to be discussed in order to improve the level of economy and technology.

Low temperature thermal power generation is an important form of energy recovery in a variety of technical ways of low temperature heat utilization (power generation, refrigeration, heat pump, etc.). There are 4 main types of low-temperature thermal power generation technology used in petrochemical enterprises: (1) the expansion of flash steam generation technology (2) power generation technology of low pressure saturated steam (3) Karina power cycle power generation technology (4) organic Rankine cycle power generation technology.

With the increase of crude oil price and the research of energy optimization, the recovery and utilization of low temperature waste heat in oil refining industry has been paid more and more attention, and it is becoming one of the most important aspects of energy saving in refineries[7].

Other industry. The above is about the main energy consuming industries. In addition, the use of waste heat in building materials, light industry, textile, coal, machinery and other industries and fields are also getting more and more attention. There have been many combined with the production of waste heat utilization method.

For example, the building materials industry, it is mainly concentrated in the consumption of heat and drying process. The energy utilization rate of China's ceramic industry is $28 \%-30 \%$, while the energy utilization rate of developed countries is generally as high as $50 \%$ [8]. At present, in order to increase the utilization of waste heat, our country has gradually begun to promote the use of kiln waste heat heating directly or spray dried body mud, in the heat exchanger with flue gas heating the combustion air and gaseous fuel, waste heat boiler steam production and for heat and power cogeneration. 


\section{The development of waste heat utilization technology}

Heat pipe technology. Heat pipe is a new type heat transfer element which is composed of shell and working fluid. It has a strong thermal conductivity. Heat pipe technology is a kind of heat transfer technology in 1960s. The heat pipe can be made by filling the heat conducting medium in the steel, copper and aluminum tubes which are completely closed.

As a new technology of waste heat recovery and utilization, heat pipe technology is an effective method to recover the waste heat of the exhaust gas and the waste heat of sintering flue gas. The heat pipe waste heat recovery technology makes full use of the principle of the phase change heat transfer, which has a series of characteristics, such as high reliability, high thermal conductivity, good thermal stability, high heat flux variability and environmental adaptability.

At present, the heat pipe technology has been widely used in the waste heat utilization of electric power, metallurgy, petrochemical, light industry and other industries. In the iron and steel enterprises, it is different from the previous flue gas through a variety of heat exchangers and waste heat boiler into steam or hot water heat utilization. The heat pipe waste heat generator can directly utilize the waste heat of the flue gas. The technology has remarkable energy saving effect and excellent economic benefit. Therefore, it has a very good promotion value and application prospect.

Pure low temperature waste heat power generation technology. The use of pure low temperature waste heat power generation technology to recover the waste heat of cement kiln has been used as one of the ten key energy-saving projects in China in 11th Five-Year.

Pure low temperature waste heat power generation system is developed on the basis of low temperature waste heat power generation technology. Through these years of practice to many production line of the waste heat boiler in our country, several major design institutes and manufacturers initial grasp of the principle of cement kiln waste heat boiler structure design and performance design, and solve many problems in the operation of exposure, such as boiler air leakage, ash, wear and corrosion etc.. The cement factory burned into the running status of the system is the basis of supporting waste heat power generation system. The residual heat can be used in cement plant is different. There are different requirements for the design of pure low temperature waste heat power generation system is generally divided into three kinds[9]: (1) by condensing steam turbine into single pressure steam. The system is simple and reliable (2) using the waste heat boiler to generate double pressure steam, and the steam turbine. The reliable equipment and system operating rate can be guaranteed under the premise, the system efficiency is higher than that of steam turbine unit; (3) the use of waste heat boiler and hot water flash double pressure steam produced matching up condensing steam turbine unit. This process has high power generation efficiency. In these 3 systems, the single pressure system is simple and reliable, the power generation capacity is low, and the power generation capacity of the dual pressure system is relatively high.

There is pure low temperature waste heat power generation by using waste heat generated in the production of cement. The entire power system does not involve any primary energy. The construction of pure low temperature waste heat power station can not only reduce the cost of electricity generation, but also can ease the tension of the tension. In addition, the recovery of waste heat can reduce emissions of polluting gases and achieve energy-saving emission reduction.In this way, environment can be protected better.

Organic Rankine cycle power generation technology (ORC). ORC is a low boiling point organic refrigerant Rankine cycle. The principle of thermal cycle is the same as that of the conventional steam power plant, but the working fluid is different. In this way, the waste heat is not directly contacted with the working fluid. Because of the small volume, small size and high power 
per unit volume, it is suitable for low temperature waste heat recovery.

In the organic Rankine cycle power recovery device, refrigerant plays a role of energy transfer and conversion. Therefore, the characteristics of the working fluid determine the structure and energy efficiency of the whole system. In recent years, through the theoretical analysis and experimental study of domestic and foreign scholars, it is concluded that YISHION working fluid is more suitable for engineering application.

The study of ORC in China started late, and the related research work is not enough. At present, our country is carrying out the engineering research and the key technology research and development of ORC, and promote the application of ORC to engineering application actively.

\section{Conclusion}

China's industrial waste heat resources are abundant. It exists in various industrial sectors widely. The utilization rate of waste heat utilization is large, and the energy saving potential is huge.

Industrial waste heat recovery and utilization is an important part of energy conservation and emission reduction in china. Therefore, it is necessary to analyze and diagnose all kinds of waste heat resources, and innovate the advanced waste heat recovery technology actively. Only in this way can we recycle and utilize the waste heat resources more efficiently, and promote the construction of environment-friendly and resource-saving society comprehensively.

\section{Reference}

[1] Y.Lin.COP15 United Nations Climate Change Conference Copenhagen 2009[EB/OL].[2009-12-05].http://www.hudong.com/wiki/\%E5\%93\%A5\%E6\%9C\%AC\%E5\% 93\%88\%Е6\%АO\%В9\%Е4\%ВC\%9А\%Е8\%АЕ\%АЕ.

[2] H.L. Li,Y.M. Wen and D.M. Sun.Feasibility of Electric Power Self-Support in Iron and Steel Enterprise[J].Iron and Steel,2010,(1).(In Chinese)

[3] R.X. Zhang. Heat balance and energy saving technology.Background:Metallurgical industry press. 1993.(In Chinese)

[4] J. Meng.Optimization research for the recovery and utilization of waste heat in the industrial flue gas[D]. Wuhan: School of Energy and Power Engineering,Huazhong University of Science\&Technology.2008. (In Chinese)

[5] C.H. Wu.Analysis on waste heat and surplus energy using in iron and steel enterprise [J].Energy for Metallurgical Industry,2014(02). (In Chinese)

[6] A.L. Gu.Energy saving and emission reduction potential and cost analysis of Chinese cement industry.China Population,Resources and Environment.2012,22(8):16-21(In Chinese)

[7] J.J. Xu. Petroleum Refinery Engineering,2006,36(4):47-50.(In Chinese)

[8] F.P. Huang,Z. Li and Y. Li. Discussion on Energy saving technology of Thermal equipment in Building ceramics industry [J].Xi'an Univ.of Arch.\&Tech.(Natural Science Edition).2008(6). (In Chinese)

[9] T. Chen,H. Cao. Low temperature and residual heat power generation technology and its benefit analysis in cement industry.Cement Guide for New Epoch.2005(2) (In Chinese). 
